\title{
Analisis Hubungan Beban Kerja Terhadap Keluhan Muskuloskeletal Pada Tenaga Kependidikan Di UPN Veteran Jakarta
}

\author{
Suci Wahyu Ismiyasa ${ }^{1}$, Eko Prabowo ${ }^{2}$ \\ ${ }^{1,2)}$ Program Studi Fisioterapi, Universitas Pembangunan Nasional Veteran Jakarta, Jakarta, Indonesia \\ *) e-mail korespondensi : Suciwahyuismiyasa@upnvj.ac.id
}

Tanggal Submisi: 22 Desember 2020; Tanggal Penerimaan: 21 Juni 2021

\begin{abstract}
ABSTRAK
Latar Belakang : Untuk mengetahui apakah di suatu tempat kerja mempunyai pekerja yang memiliki beban kerja dan keluhan muskuloskeletal berlebih atau kurang memiliki hubungan. Salah satu yang ingin dilihat dalam beban kerja pada penelitian ini adalah konsumsi oksigen dengan mengukur denyut nadi. Keluhan muskuloskeletal dengan menggunakan kuesioner nordic body maps. Tujuan Penelitian: Penelitian ini dilakukan untuk mengetahui hubungan dampak beban kerja terhadap keluhan muskuloskeletal terutama pada fisik seseorang. Yang akan di teliti adalah bagian tenaga kependidikan UPN Veteran Jakarta. Tujuannya agar pekerja dapat merasa ENASE (Efektif, Nyaman, Aman, Sehat dan Efisien) dalam melaksanakan tugas-tugas yang diberikan. Sebagai langkah selanjutnya dapat dilakukan perbaikan kerja seperti dari sikap kerjanya, posisi kerja, pola kerja dan lain-lain. Metode : Penelitian cross sectional, Instrumen penelitian : Alat oxiometric untuk mengukur $\mathrm{SpO}_{2}$ dan Nordic Body Map untuk mengukur keluhan muskuloskeletal. Hasil : Sampel yang diperoleh berjumlah 60 orang. Dilakukan uji analisis univariat dan bivariat. Data berdistribusi normal dengan uji kolomogorov smirnov. Hasil uji spearmen dengan nilai $p=$ 0,036 berarti $\mathrm{p}<0,05$ maka ada hubungan beban kerja dan keluhan muskuloskeletal pada tenaga kependidikan UPN Veteran Jakarta. Simpulan : Beban kerja yang didapat oleh tenaga kependidikan UPN Veteran Jakarta ringan, hal ini dapat dilihat dari hasil $\mathrm{HR}$ dan $\mathrm{SpO}_{2}$, Rata-rata tenaga kependidikan UPN Veteran Jakarta mengalami keluhan muskuloskeletal dengan kondisi rendah, Usia dan jenis kelamin apapun akan mengalami keluhan muskuloskeletal.
\end{abstract}

Kata Kunci : Beban Kerja, Keluhan Muskuloskeletal, Tenaga Kependidikan

\section{ABSTRACT}

Background:. This is to find out whether a workplace has workers who have an excessive or less related workload and musculoskeletal complaints. One thing that wants to be seen in the workload in this study is oxygen consumption by measuring the pulse. Musculoskeletal complaints using a nordic body map questionnaire. Research Objectives: This research was conducted to determine the relationship between the impact of workload on musculoskeletal complaints, especially on a person's physical condition. What will be examined is the educational staff of UPN Veteran Jakarta. The goal is that workers can feel ENASE (Effective, Comfortable, Safe, Healthy and Efficient) in carrying out the assigned tasks. As a next step, work improvements can be made such as from their work attitude, work position, work patterns and others. Methods: cross sectional research. Research instruments: An oxiometric tool for measuring $\mathrm{SpO}_{2}$ and a Nordic Body Map for measuring musculoskeletal complaints. Results:. The sample obtained was 60 people. Univariate and bivariate analysis tests were performed. Data were normally distributed using the Colomogorov Smirnov test. The results of the spearmen test with a value of $p=0,036$ means $p<0.05$, so there is a relationship between workload and musculoskeletal complaints on the UPN Veteran Jakarta education staff. Conclusion: The workload obtained by UPN Veteran Jakarta education staff is light, this can be seen from the results of $\mathrm{HR}$ and $\mathrm{SpO}_{2}$. On average, UPN Veteran Jakarta education personnel experience musculoskeletal complaints with low conditions, age and any gender will experience musculoskeletal problems. 


\section{Keywords : workload, Musculoskeletal problem, Education Staff}

\section{PENDAHULUAN}

Tubuh membutuhkan kondisi dimana bisa bergerak, mendapatkan asupan dan beristirahat. Jika kondisi-kondisi tersebut tidak seimbang maka tubuh akan menerima kondisi yang berlebihan pada kondisi di satu sisi. Misalnya jika tubuh berlebihan dalam bergerak dan tidak ada istirahat, tubuh akan mudah lelah. Adapun jika berlebihan dalam mendapatkan asupan dan kurang bergerak maka tubuh akan menjadi gemuk.

Dalam bekerja terdapat 2 faktor yang mempengaruhi seorang yaitu tindakan dan kondisi yang tidak aman.Tindakan yang tidak aman adalah perlakuan yang sesuai ketika bekerja, dimana penyebabnya telah ditentukan akibat tidak seimbangnya fisik dan pengetahuan yang minim. Kondisi yang tidak aman adalah kondisi sekitar yang tidak mendukung dalam beraktifitas seperti alat bantu kerja yang berbahaya. (Irzal, 2016)

Kelelahan, nyeri dan gangguan kesehatan lainnya menyebabkan performa kerja yang tidak ergonomis. Ergonomi adalah disiplin ilmu yang bersifat multidisipliner dimana terintegrasi ilmu fisiologi, psikologi, anatomi, hygiene, sosial budaya, ekonomi dan ilmu lainnya yang berkaitan dengan pekerjaan. Dalam hal ini berhubungan dengan manusia dan lingkungan pekerjaanya di pelajari yaitu ilmu ergonomi. (Santoso, 2013)

Beban kerja merupakan sejumlah proses kegiatan yang harus diselesaikan oleh seorang pekerja dengan waktu tertentu. Jika kemampuan pekerja lebih tinggi daripada tuntutan pekerjaan, akan terjadi rasa bosan. Apabila pekerja tersebut mempunyai kemampuan yang lebih rendah daripada tuntutan pekerjaan, maka akan terjadi kelelahan yang berlebihan. Sehingga jika suatu perusahaan mempunyai pekerja yang bermasalah dalam beban kerja maka harus dilakukan evauasi agar produktivitas pada pada pekerja tersebut baik dan sesuai apa yang di harapkan.(Hasibuan \& Banjarnahor, 2019)
Berbagai macam pengukuran beban kerja yang banyak di lakukan perusahaan salah satunya adalah mencari konsumsi oksigen/HR (heart rate) dan dengan memakai kuesioner. Pulse oximetry adalah jalan untuk mengukur seberapa banyak oxygen dalam darah yang dibawa. Dengan menggunakan peralatan kecil yang dinamakan pulse oxiometer, level oxygen dalam darah yang di cek tanpa perlu menggunakan jarum. Pengukuran level oxygen dalam darah dengan oxiometer disebut level saturation oxygen (disingkat $\mathrm{O}_{2}$ sat atau $\mathrm{SpO}_{2}$ ). Presentase ini seberapa banyak oxygen dalam darah yang dibawa dibandingkan ke maksimum yang dapat dibawa. Normalnya, lebih dari $89 \%$ dari darah merah yang dibawa oxygen.(Nimbalkar, 2015)

Salah satu pendekatan untuk mengukur gangguan muskuloskeletal adalah dengan menggunakan alat ukur keluhan musculoskeletal yang disebut Nordic Body Map. Metode ini merupakan alat ukur yang sangat subjektif dimana tingkat validitas metode ini sangat tergantung dari keahlian dan keadaan yang dialami ketika penelitian. Selain itu, alat ukur dengan kuesioner ini telah secara luas digunakan oleh para ahli ergonomi dalam menilai tingkat keparahan pada keluhan musculoskeletal (Tarwaka, 2011).

\section{METODE}

Penelitian ini memakai desain penelitian deskriptif korelasional dengan rancangan penelitian yang digunakan adalah cross sectional. Desain penelitian ini memaparkan apakah beban kerja pada tiap-tiap karyawan sudah sesuai dengan tuntutan pekerjaanya. Sumber data yang diterima merupakan data primer berupa penghitungan HR atau kadar O2 dan kuesioner Nordic Body Map. Subjek penelitian ini adalah tenaga kependidikan di lingkungan UPN Veteran Jakarta. 
Teknik Pengumpulan data : 1) Memilih calon respoden sesuai dengan kriteria inklusi dan eksklusi , 2) Menghampiri para calon responden dengan disertai membawa surat permohonan dan kuesioner, kemudian memberikan penjelasan tentang tujuan penelitian, 3) Peneliti memaparkan tentang tahapan penelitian setelah calon responden bersedia menjadi responden, 4) Responden menandatangi lembar persetujuan dihadapan peneliti, 5) Peneliti melakukan pemeriksaan oximeter kepada responden.

Analisis data dalam penelitian ini menggunakan analisis univariat terdiri atas umur, Jenis Kelamin, Heart Rate, Saturasi Oksigen, Keluhan Muskuloskeletal dan bivariat terdiri dari beban kerja dan keluhan muskuloskeletal

\section{HASIL DAN PEMBAHASAN}

Deskripsi data sampel dilakukan dengan analisis univariat untuk mengetahui frekuensi dan presentase umur, jenis kelamin, heart rate, saturasi oksigen dan keluhan muskuloskeletal. Kemudian, bivariat untuk mengetahui hubungan beban kerja dan keluhan muskuloskeletal.

Tabel 1 Distribusi Univariat Untuk Mengetahui Frekuensi Dan Presentasi Umur, Jenis Kelamin, Heart Rate, Saturasi Oksigen, Dan Keluhan Muskuloskeletal

\begin{tabular}{clcc}
\hline No & \multicolumn{1}{c}{ Variabel } & $\begin{array}{c}\text { Frekuens } \\
\mathrm{i}\end{array}$ & $\begin{array}{c}\text { Persentas } \\
\mathrm{e}(\%)\end{array}$ \\
\hline 1. & Usia & & \\
& 17-25 Tahun & 14 & 22,2 \\
& 26-35 Tahun & 24 & 38,1 \\
& 36-45 Tahun & 9 & 14,3 \\
& 46-55 Tahun & 11 & 17,5 \\
& 56-65 Tahun & 2 & 3,2 \\
2. Jenis Kelamin & & \\
& Laki-laki & 26 & 43,3 \\
& Perempuan & 34 & 56,7 \\
3. Hearth Rate & & \\
& Sedang & 9 & 85 \\
& Ringan & 51 & 15 \\
& & & \\
4. & SpO 2 & & \\
Normal & 57 & 98 \\
& Tidak Normal & 3 & 2
\end{tabular}

5. Keluhan

Muskuloskeleta

1

\begin{tabular}{lcc} 
Normal & 3 & 2 \\
Tidak Normal & 57 & 98 \\
\hline
\end{tabular}

Dari gambaran distribusi tersebut dapat dilihat bahwa beban kerja yang diterima pada tenaga kependidikan UPNVJ menyebabkan keluhan muskuloskeletal dengan tingkat yang ringan, ini dapat dilihat dari HR dan $\mathrm{SpO}_{2}$ dengan rata-rata jumlah diatas $50 \%$ yang menandakan beban kerja yang diterima ringan atau tidak terlalu tinggi beban kerjanya.

Analisis Hubungan Beban Kerja dan Keluhan Muskuloskeletal pada Tenaga Kependidikan UPN Veteran Jakarta

\section{Uji Normalitas}

Hasil dari analisis bivariat Hubungan beban kerja dan keluhan muskuloskeletal. Sebelum dilakukan uji bivariat maka terlebih dulu dilakukan uji Normalitas. Uji normalitas akan dilakukan dengan Kolomogorov-Smirnov. Uji ini dilakukan unuk memenuhi ketentuan pengujian uji statistik. Uji statistik tersebut adalah uji statitik paramerik untuk yang berdistribusi normal dan non paramerik untuk yang berdistribusi tidak normal

Tabel 2 Uji Normalitas Beban Kerja dan Keluhan Muskuloskeletal

\begin{tabular}{ll}
\hline \multicolumn{1}{c}{ Kategori } & Nilai Uji \\
\hline Beban Kerja & 0,000 \\
Nordic Body Map & 0,000 \\
\hline
\end{tabular}

\section{Uji Bivariat}

Hasil Uji hubungan menggunakan Spearmen: Hasil $p<0,05$ maka hipotesis ditolak

Tabel 3 Uji Spearmen

\begin{tabular}{ll}
\hline Kategori & $\mathrm{P}$ \\
\hline Beban & 0,036 \\
kerja\& & \\
NBM & \\
\hline
\end{tabular}


Berdasarkan tabel diatas diperoleh $\mathrm{p}<$ 0,05 maka ada hubungan signifikan antara beban kerja dan keluhan muskuloskeletal.

\section{KESIMPULAN}

Setelah dilakukan penelitian evaluasi beban kerja dan keluhan muskuloskeletal pada tenaga kependidikan UPNVJ, maka berdasarkan hasil penelitian dapat disimpulkan :

1. Beban kerja yang didapat oleh tenaga kependidikan UPNVJ ringan, hal ini dapat dilihat dari hasil $\mathrm{HR}$ dan $\mathrm{SpO}_{2}$.

2. Rata-rata tenaga kependidikan UPNVJ mengalami keluhan muskuloskeletal dengan kondisi rendah.

3. Usia dan jenis kelamin apapun akan mengalami keluhan muskuloskeletal

4. Ada hubungan yang signifikan antara beban kerja dan keluhan muskuloskeletal

\section{UCAPAN TERIMA KASIH}

Terima kasih kepada institusi Universitas Pembangunan Nasional Veteran Jakarta yang telah memberikan dana pada Kegiatan Penelitian

\section{DAFTAR PUSTAKA}

Irzal. (2016). Dasar-dasar Kesehatan dan Keselamatan Kerja. Jakarta: Kencana.

Kroemer, K. E., \& Grandjean, E. (1997). Fitting the Tas to the Human. London: Taylor \& Francis.

Kuswana, W. S. (2014). Ergonomi dan K3 Kesehatan dan Keselamatan Kerja. Bandung: Remaja Rosdakarya.

Lemeshow S,et al.1996. Besar Sampel Dalam Penelitian Kesehatan. Gajah Mada University Press Yogyakarta

Santoso, G. (2013). Ergonomi Terapan. Jakarta: Prestasi Pustaka 